\title{
In Vitro Study of Shear Bond Strength in Direct and Indirect Bonding with Three Types of Adhesive Systems
}

\author{
Angelica Iglesias ${ }^{1}$, Teresa Flores ${ }^{1}$, Javier Moyano ${ }^{1}$, Montserrat Artés ${ }^{1}$, Francisco Javier Gil ${ }^{2}$ \\ and Andreu Puigdollers 1,* \\ 1 Department of Orthodontics, Universitat Internacional de Catalunya, 08195 Barcelona, Spain; \\ angelica@uic.es (A.I.); mflorfra@uic.es (T.F.); jmoyano@uic.es (J.M.); martes@uic.es (M.A.) \\ 2 Bioengineering Institute of Technology, Universitat Internacional de Catalunya, 08195 Barcelona, Spain; \\ xavier.gil@uic.cat \\ * Correspondence: andreup@uic.es; Tel.: +34-61-028-9450
}

Received: 28 April 2020; Accepted: 8 June 2020; Published: 10 June 2020

\begin{abstract}
This study aimed to compare the shear bond strength (SBS) and adhesive remaining index (ARI) using one conventional and two novel adhesive systems with clinical step reduction and direct and indirect bonding. A sample of 72 human premolars were divided into six groups of 12 samples. The first three groups (G1, G2, G3) were bonded with a direct technique, while the remaining groups (G4, G5, G6) were bonded by the indirect technique. Groups G1 and G4 used conventional acid-etching primer composite $(\mathrm{XT})$; groups $\mathrm{G} 2$ and G5 used self-etching bonding (BO), and groups G3 and G6 had an acid-etching treatment followed by a self-adhesive composite (OC). All groups were exposed to thermocycling. Shear bond strength was analyzed with a universal test machine, and the ARI was examined with $4 \times$ magnification. The results showed statistically significant differences between the three adhesive systems. The highest strength values were observed in the XT group G1 $(13.54 \pm 4 \mathrm{MPa})$, while the lowest were shown in the BO G2 samples ( $5.05 \pm 2 \mathrm{MPa})$. There was no significant difference between the direct or indirect bonding techniques on the three compared groups. The type of primer and bonding material significantly influenced the SBS. Values with self-etching bonding were below the minimum recommended for clinical use (5.9-7.8 MPa). There was no difference between indirect and direct bonding techniques. The lowest ARI scores (0-1) were observed in both self-etching and BO groups. Further clinical studies are needed to compare in vivo results.
\end{abstract}

Keywords: self-etch; self-adhesive; indirect bonding; shear bond strength

\section{Introduction}

Since the introduction of the first bonding systems, there has been a constant effort to improve the quality of materials [1]. Researchers [2,3] have developed new adhesives based on the need to increase shear bond strength (SBS), decrease bonding time, achieve an efficient reduction of the clinical bonding steps, and preserve the enamel. Bond strength should be of an optimum force rather than too much or too little [2]. According to Reynolds [4], the minimum bond strength should be in the range of 5.9-7.8 MPa to withstand masticatory forces. Excessive bond strength forces (greater than 40-50 MPa), increase the risk of enamel damage during debonding and should be avoided; while bond failures during treatment are a consequence of insufficient bond strength values and are also not desirable $[2,5]$. Therefore, the nature of the adhesive is of great importance in regard to the bond strength, composite left on teeth, and enamel injury [6]. Enamel loss at debonding reaches up to $120.6-189.98 \mu \mathrm{m}$. An additional $10-30 \mu \mathrm{m}$ is affected by the previously performed acid-etching process, 
and $55.6 \mu \mathrm{m}[7,8]$ is lost in the removal of the remnant adhesive after debonding. It could be assumed that these values multiply every time a bracket is re-bonded [2].

Conventional adhesive systems use three different agents during the bonding process: an enamel conditioner, a primer solution, and an adhesive resin. Phosphoric acid has remained the primary enamel etchant since its introduction by Buonocore [9], despite the enamel loss previously described. New etching systems have tried to solve this problem, adding fluoride releasable components to protect the enamel, and using adhesive cements [10] or developing less detrimental components for the etching of the enamel by a combination of conditioning (Phenyl-P) and priming (HEMA and dimethacrylate) agents into a single acidic primer solution. These so-called self-etching primers can be used on enamel and dentin in a single step [11]. Numerous comparative studies between conventional and self-etching adhesives have been performed to determine the effectiveness of adherence in both techniques [12,13]. In addition, some of the studies claim that the gentler components of self-etching primers produce less enamel loss than phosphoric acid [14,15].

Indirect bonding (IB) has emerged in recent years as the best option to achieve a precise bracket placement. The technique introduced was by Silverman [16], and modified by Thomas [17], and has become the basis of current indirect bracket bonding methods. It consists of positioning the bracket in a laboratory working cast, followed by the fabrication of a transference tray to assure correct bonding in the patient. With a direct vision of the cast model, accurate placement of the bracket, less chair time [18], less patient discomfort, and improved ability to bond posterior teeth are some of the advantages that have been described [19-21]. Additionally, due to prior bracket placement in the laboratory, it has been suggested that IB allows more accurate bracket positioning $[17,21,22]$.

Classification of samples according to the adhesive remnant index (ARI) reveals information about the bracket bonding enamel interface and has great value concerning the enamel condition after debonding. Lower values tend to show less damage on the surface of the enamel and are rarely related to enamel fractures, but can be related to insufficient bond strength. On the contrary, higher ARI values are shown in efficient unions between adhesive and enamel, but are often associated with greater surface damage [23].

A novel bonding protocol involving new adhesive systems that reduce steps during bonding, such as self-etching or self-adhesive methods, is of great clinical interest among orthodontists. It would also be of interest to incorporate the indirect bonding technique, given its previously mentioned advantages. Therefore, the aim of this in vitro study was to evaluate the efficiency of three types of bonding systems: a conventional acid-etching composite, a self-etching adhesive method, and a new self-adhesive composite, in combination with two bonding techniques (direct and indirect bonding). The efficiency of the systems was evaluated by computation of the shear bond strength (SBS) and the adhesive remnant index (ARI), aiming to obtain information that helps to develop the best adhesion protocol for further clinical studies.

\section{Materials and Methods}

\subsection{Sample Size}

A preliminary pilot study was conducted to test the methodology. After pilot study analysis, sample size calculation was set to achieve a statistical power of $80 \%$ with a significance level of $5 \%$, taking into account a 2.5 standard deviation. A sample of 12 premolars per group was estimated. With this data, a study protocol was developed and approved by the ethics committee at the Universitat Internacional de Catalunya (Sant Cugat, Barcelona, Spain).

\subsection{Sample Preparation}

Seventy-two freshly extracted premolars showing no decay or fractures were introduced into $0.9 \%$ physiological saline and stored at $37^{\circ} \mathrm{C}$. The three tested bonding materials are shown in Table 1 . All samples were cleaned, and organic residues were removed with gauze. The bonding surface was 
abraded with a cup and fluoride-free prophylaxis paste (Detartrine, Septodont, Saint-Maur-des-Fossés, France) at low speed, applied by a handpiece (10 s), and posteriorly washed with water and dried with oil-free compressed air. Afterward, the sample was randomly divided into 6 groups according to the type of adhesive and bonding technique (Table 2), with 12 premolars per group.

Table 1. Composition of tested adhesive systems.

\begin{tabular}{|c|c|c|c|}
\hline Bonding Material & Manufacturer & Components & Composition \\
\hline $\begin{array}{c}\text { XT } \\
\text { Transbond XT }\end{array}$ & $\begin{array}{l}\text { 3M Unitek, } \\
\text { Monrovia, } \\
\text { California, USA }\end{array}$ & $\begin{array}{l}\text { Etching Gel } \\
\text { Primer } \\
\text { Paste }\end{array}$ & $\begin{array}{c}\text { 37\% phosphoric acid, tetraethyleneglycol } \\
1.39 \text { dimethacrylate (TEGDMA), bisphenol A } \\
\text { diglycidyl methacrylate (BIS-GMA); Bis-GMA, } \\
\text { TEGDMA, silane-treated quartz, amorphous silica, } \\
\text { camphorquinone }\end{array}$ \\
\hline $\begin{array}{l}\text { BO } \\
\text { Beauty Orthobond } \\
\text { II }\end{array}$ & $\begin{array}{l}\text { Shofu, Kyoto, } \\
\text { Japan }\end{array}$ & $\begin{array}{l}\text { Primer A } \\
\text { (self-etching) } \\
\text { Paste }\end{array}$ & $\begin{array}{l}\text { Water, solvent, phosphoric acid monomer, ethanol, } \\
\text { TEDGMA, surface pre-reacted glass-ionomer, filler, } \\
\text { Bis-GMA, camphorquinone }\end{array}$ \\
\hline $\begin{array}{c}\text { OC } \\
\text { GC Ortho Connect }\end{array}$ & $\begin{array}{l}\text { GC America, } \\
\text { Alsip, Illinois, } \\
\text { USA }\end{array}$ & $\begin{array}{l}\text { Etching Gel } \\
\text { Paste } \\
\text { (self-adhesive) }\end{array}$ & $\begin{array}{l}\text { 37\% phosphoric acid (7.7.9-trimethyl-4.13-dioxo- } \\
\text { 3.14-dioxa-5.12-diazahexadecane-1.16-diyl } \\
\text { bismethacrylate) }\end{array}$ \\
\hline
\end{tabular}

Table 2. Study design of the groups to compare the shear bond strength (SBS) and the adhesive remaining index (ARI) using three adhesive systems and two bonding techniques (direct and indirect bonding).

\begin{tabular}{ccccccc}
\hline Bonding Protocol & G1 & G2 & G3 & G4 & G5 & G6 \\
\hline Adhesive & XT & BO & OC & XT & BO & OC \\
\hline Bonding Technique & Direct & Direct & Direct & Indirect & Indirect & Indirect \\
\hline
\end{tabular}

All samples were mounted with a custom-made jig, as described by Flores et al. [12], to standardize the position of the teeth. The buccal surface of the teeth was set parallel to the direction of the shear during mechanical debonding tests. Samples of the direct bonding groups were mounted individually, and the indirect bonding samples were mounted in groups of 4 teeth per block (Figure 1). For the indirect bonding groups, a cast of the block-mounted units was made with a silicone impression (Hydrorise Putty Fast, Zhermack, Marl, Germany), and hard stone (Elite Model, Zhermack, Marl, Germany) was poured into the impression. The cast was burnished with a separator (Prothyl Isolator, Zhermack, Marl, Germany) and left to dry at ambient temperature for $1 \mathrm{~min}$. The next step was the positioning of the premolar brackets (Victory Series, 3M Unitek, Monrovia, CA, USA) [12].

A

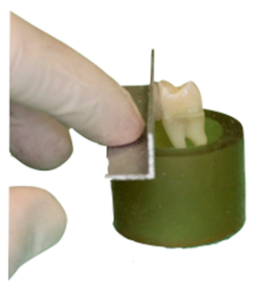

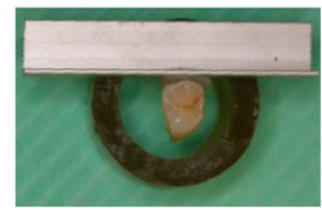

\section{B}
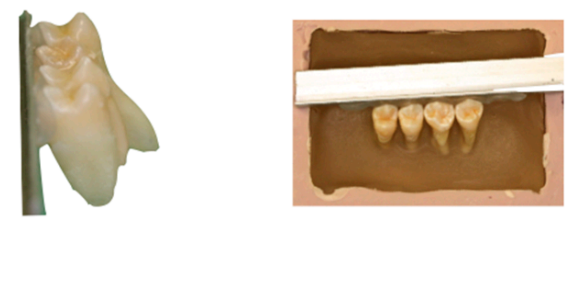

Figure 1. Representative images of mounting jigs. (A) Direct bonding samples, (B) Indirect bonding samples. 


\section{Group 1: TX/Direct Bonding}

The teeth were pre-treated with $37 \%$ orthophosphoric acid for $30 \mathrm{~s}$ and irrigated with water for $10 \mathrm{~s}$ before the adhesion procedure of the brackets. The bonding protocol was followed according to the manufacturer's instructions. Proper drying of the enamel after etching was performed, followed by the application of a thin layer of Transbond XT primer (3M Unitek, Monrovia, CA, USA) on the tooth surface. Then, a small amount of composite was dispensed in the mesh, and bracket positioning was undertaken with a constant low pressure and removal of excess material. Finally, it was polymerized for $30 \mathrm{~s}$ (10 mesial, 10 distal, and 10 occlusal) with a LED lamp (Bluephase, Ivoclar Vivadent AG, Schaan, Liechtenstein).

\section{Group 2: BO/Direct bonding}

In this group, we used a self-etching composite based on a single bottle primer presentation and the composite Beauty Ortho Bond II (Shofu, Kyoto, Japan). It enabled us to do the priming and etching in a single step, following the manufacturer's instructions. The self-etching primer was applied on the enamel surface by rubbing for $3 \mathrm{~s}$ without previous acid-etching. Then, the surface was dried with low pressure, and the bracket was placed using the Beauty Ortho Bond II light-cured composite by direct bonding. The photopolymerization was done in the same way as that in group 1.

\section{Group 3: OC/Direct Bonding}

The teeth were pre-treated with $37 \%$ orthophosphoric acid for $30 \mathrm{~s}$ and irrigated with water for $10 \mathrm{~s}$ before the adhesion procedure of the brackets. Proper drying at a low speed was carried out, and we proceeded to spread the self-adhering composite GC Ortho Connect onto the bracket mesh. The positioning of the bracket was carried out with a low and constant pressure and posterior removal of excess material. Finally, we proceeded with photopolymerization, using an LED light (Bluephase, Ivoclar Vivadent AG, Schaan, Liechtenstein) for $30 \mathrm{~s}$ (10 mesial, 10 distal, and 10 occlusal).

\section{Group 4: TX/Indirect bonding}

For the indirect bonding, we obtained cast models as previously described, in which marks were made for the positioning of the bracket. The bracket was then positioned with Transbond XT and LED light-curing of $20 \mathrm{~s}$ per bracket. Once the brackets were placed in the cast, we continued the fabrication of the transference tray with Elite Glass (Zhermack, Marl, Germany) that was applied to the cast by a mixing pistol in a uniform way over the teeth with a work time of $40 \mathrm{~s}$ and $2 \mathrm{~min} 15 \mathrm{~s}$ of setting time in a $23{ }^{\circ} \mathrm{C}$ temperature. Once we had obtained the transference tray, we removed it from the cast with the bracket and proceeded with the sandblasting.

For the treatment of the natural teeth, 37\% orthophosphoric acid was applied for $30 \mathrm{~s}$, posterior irrigation with water occurred for $10 \mathrm{~s}$, the drying of the surface was carried out as in previous groups, and the application of the primer followed the manufacturing instructions. We then placed a fine layer of composite in the bracket mesh and made the transference tray with light-curing for $30 \mathrm{~s}$ (Figure 2).

Group 5: BO/Indirect Bonding

In this group, we applied the same protocol to natural teeth as in group 2, and the transference tray was made as described in group 4 .

Group 6: OC/indirect group

In this group, we applied the same protocol to natural teeth as in group 3, and the transference procedure was the same as described in group 4. 

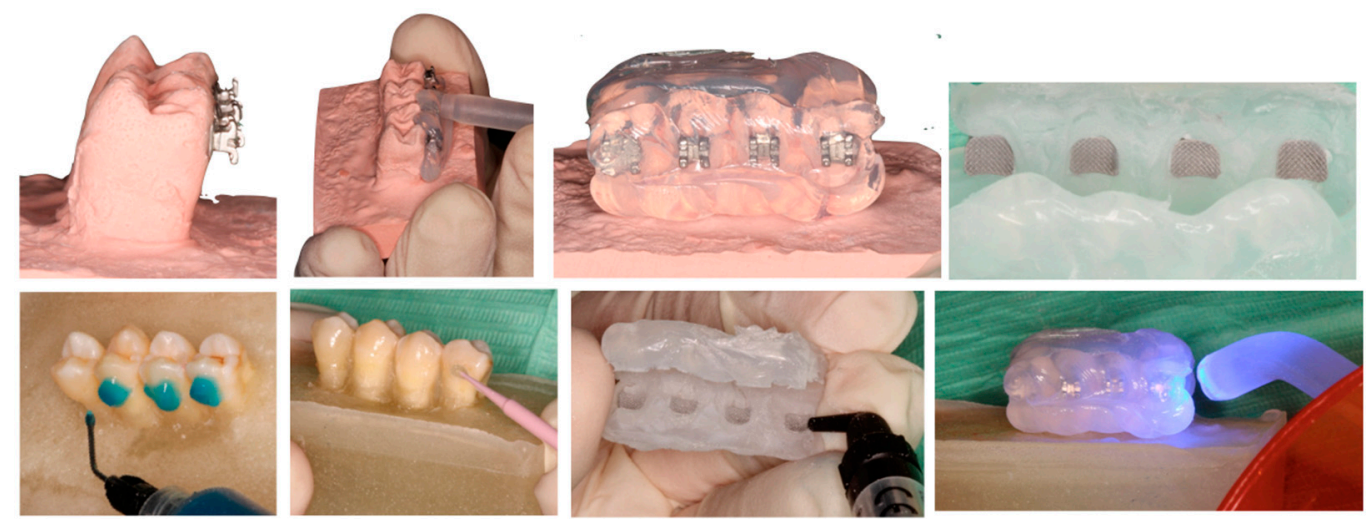

Figure 2. Representative images of indirect bonding samples steps (group 4).

\subsection{Thermocycling}

The tooth samples were stored with hydration in a physiological saline solution of $0.9 \%$ at $37^{\circ} \mathrm{C}$. All groups were exposed to thermocycling before debonding $24 \mathrm{~h}$ after bracket placement. The thermocycling consisted of 1500 cycles in a water bath at 5 and $55^{\circ} \mathrm{C}$, with bath times at 1 min intervals.

\subsection{Debonding Resistance Test}

We tested the samples of all the different groups with a universal testing machine (Quasar 5, Galdabini, Cardano al Campo, Italy) at a maximum speed of $0.1 \mathrm{~mm} / \mathrm{min}$ [12]. The result of the force was obtained in newtons and then converted to $\mathrm{MPa}$, dividing the force between the bracket area $\left(9.75 \mathrm{~mm}^{2}\right)$.

\subsection{Adhesive Remnant Index}

Examples of adhesive remnant index (ARI) classification and values are shown in Figure 3. Each sample was evaluated and photographed by one operator (A.I.) with a microscope at $4 \times$ magnification, and was classified based on a visual scale in which scale 0 corresponded to no adhesive remaining; 1 corresponded to less than half of the adhesive remaining; 2 corresponded to more than half of the adhesive remaining; 3 corresponded to all adhesive remaining [24].

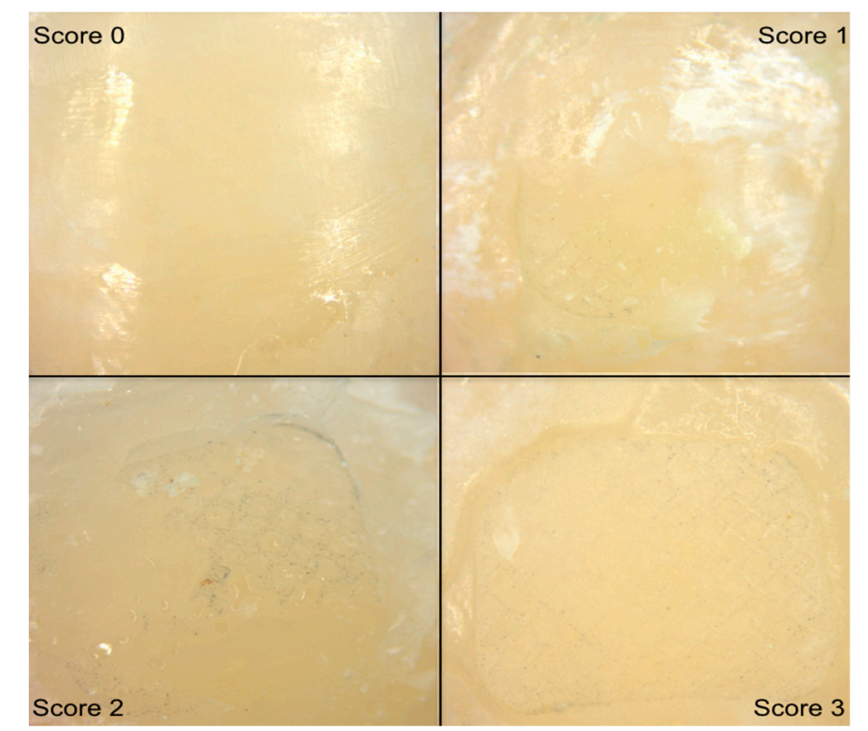

Figure 3. Representative images for adhesive remnant index (ARI) under microscopic examination. ARI 0 (no adhesive remaining); ARI 1 (less than half of the adhesive remaining); ARI 2 (more than half of the adhesive remaining); ARI 3 (all adhesive remaining). 


\subsection{Statistical Analysis}

Numerical variables were described with mean and standard deviation, while the median was described with minimum and maximum values. Categorical variables were described with frequencies and percentages.

Differences of SBS between the groups of the study were analyzed with one-way ANOVA, and the Shapiro-Wilk test was used to check the normality of residuals. In addition, a comparative post hoc test was used with Bonferroni correction.

The Kruskal-Wallis and Mann-Whitney tests were used to analyze differences in the distributions of the ARI scores.

The samples were classified based on a visual scale by one operator (A.I.), and intra-operator analysis was performed for the ARI values with a regression line of all the samples. The validity of the classification was confirmed with an 0.85 correlation coefficient.

Results were analyzed with a statistical software program (Statgraphics, Warrenton, VA, USA). The level of statistical significance was set at $p<0.05$.

\section{Results}

\subsection{Shear Bond Strength}

A description of the results of the shear bond strength is shown in Table 3 The highest strength values were observed in the acid-etching groups (OC and XT materials), with the XT direct group $(13.5 \pm 4 \mathrm{MPa})$ having the highest values. The lowest values were shown in the BO samples, with the indirect group (5.1 $\pm 2 \mathrm{MPa}$ ) representing the lowest scores (Figure 4).

One-way ANOVA showed significant effects of groups $(p<0.001)$, and we checked the normality residuals with the Shapiro-Wilk test $(p=0.103)$.

The difference between groups and multiple comparisons by t-test with Bonferroni correction are shown in Table 4, in which all acid-etching groups (XT, OC) demonstrate significant difference when compared with the self-etching groups (BO).

Table 3. Descriptive values of shear bond strength for the overall sample, levels of two factors, and the six study groups.

\begin{tabular}{ccc}
\hline Comparison & Mean (sd) & Median [Min-Max] \\
\hline Overall & $9.7(4.5)$ & $9.4[2.7-20.2]$ \\
\hline Material & - & - \\
XT $^{\mathrm{a}}$ & $12.3(4.1)$ & $12.5[4.8-20.2]$ \\
BO $^{\mathrm{b}}$ & $5.2(1.6)$ & $5.1[2.7-8.7]$ \\
$\mathrm{OC}^{\mathrm{a}}$ & $11.7(3.4)$ & $11.7[5.1-17.8]$ \\
\hline BT & - & - \\
Direct & $10.5(4.9)$ & $11.7[2.7-20.2]$ \\
Indirect & $8.9(3.9)$ & $8.2[3.3-18.6]$ \\
\hline Material:BT & - & - \\
(G1) XT-Direct & $13.5(4.0)$ & $13.7[4.8-20.2]$ \\
(G2) BO-Direct & $5.1(2.0)$ & $4.5[2.7-8.7]$ \\
(G3) OC-Direct & $12.9(3.0)$ & $13.3[5.6-17.8]$ \\
(G4) XT-Indirect & $11.1(3.9)$ & $9.6[6.9-18.6]$ \\
(G5) BO-Indirect & $5.4(1.2)$ & $5.4[3.3-7.4]$ \\
(G6) OC一-Indirect & $10.5(3.4)$ & $9.9[5.1-17.3]$ \\
\hline Different letters $\left.{ }^{\left({ }^{a}, b\right.}\right)$ show significant statistical difference.
\end{tabular}




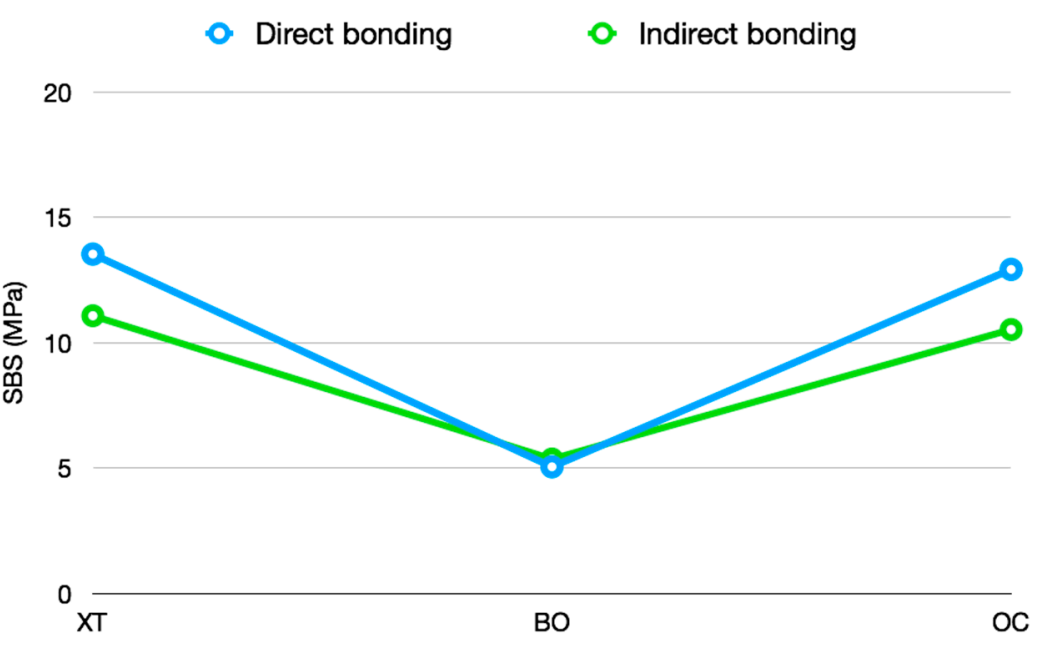

Figure 4. Mean of bonding technique interactions according to the levels of the factors material and bonding technique.

Table 4. Comparisons of SBS variable for levels of two factors and six study groups.

\begin{tabular}{cccc}
\hline Comparison & Difference & CI 95\% & $p$-Value \\
\hline Material & - & - & - \\
XT-BO & 7.10 & $5.26 ; 8.94$ & $<0.001$ \\
OC-BO & 6.52 & $11.73 ; 8.10$ & $<0.001$ \\
XT-OC & 0.58 & $-1.61 ; 2.77$ & 1 \\
\hline BT & - & - & - \\
Direct-indirect & 1.51 & $-0.60 ; 3.63$ & 0.160 \\
\hline Material: BT & - & - & - \\
G1-G5 & 8.17 & $5.56 ; 10.79$ & $<0.001$ \\
G1-G6 & 3.01 & $-0.16 ; 6.18$ & 0.316 \\
G1-G4 & 2.46 & $-0.91 ; 5.83$ & 0.871 \\
G2-G3 & -7.88 & $-10.08 ;-5.67$ & $<0.001$ \\
G2-G1 & -5.49 & $-11.23 ;-5.74$ & $<0.001$ \\
G2-G5 & -0.31 & $-1.75 ; 1.12$ & 1 \\
G2-G6 & -5.48 & $5.05 ; 10.53$ & 0.001 \\
G2-G4 & -6.03 & $-8.74 ;-3.32$ & 0.002 \\
G3-G1 & -0.61 & $-3.63 ; 2.42$ & 1 \\
G3-G5 & 7.57 & $5.54 ; 9.59$ & $<0.001$ \\
G3-G6 & 2.40 & $-0.35 ; 5.15$ & 0.958 \\
G3-G4 & 1.85 & $-1.15 ; 4.84$ & 1 \\
G5-G6 & -5.16 & $-7.43 ;-2.89$ & 0.002 \\
G5-G4 & -5.72 & $-8.30 ;-3.14$ & $<0.001$ \\
G6-G4 & -0.55 & $-3.69 ; 2.59$ & 1 \\
\hline
\end{tabular}

\subsection{Adhesive Remnant Index}

The ARI analysis by materials was performed by a Kruskal-Wallis test that showed statistically significant differences between groups $(p<0.001)$. Thus, a subsequent Mann-Whitney test with Bonferroni correction was performed to analyze the differences between them (Table 5). The results showed a significant difference between the acid-etching groups (XT, OC) and the self-etching group (BO). The XT and CT groups showed a majority of scores between 2 and 3, while BO groups showed predominant values of $0-1$ (Figure 5). There was no difference between the bonding techniques (direct and indirect bonding). 
Table 5. Frequency and percentage for overall sample, two factors, and six groups.

\begin{tabular}{cccccc}
\hline Comparison & $\mathbf{0}$ & $\mathbf{1}$ & $\mathbf{2}$ & $\mathbf{3}$ & $p$-Value \\
\hline Overall & $24(32 \%)$ & $18(24 \%)$ & $16(21.3 \%)$ & $17(22.6 \%)$ & \\
\hline Material & - & - & - & - & $<0.001$ \\
XT $^{\text {a }}$ & $2(8 \%)$ & $4(16 \%)$ & $7(28 \%)$ & $12(48 \%)$ & - \\
BO $^{\mathrm{b}}$ & $19(76 \%)$ & $4(16 \%)$ & $1(4 \%)$ & $1(4 \%)$ & - \\
OC $^{\mathrm{a}}$ & $3(12 \%)$ & $10(40 \%)$ & $8(32 \%)$ & $4(16 \%)$ & - \\
\hline BT & - & - & - & - & 0.978 \\
Direct & $11(28.2 \%)$ & $13(33.3 \%)$ & $6(15.4 \%)$ & $9(23.1 \%)$ & - \\
Indirect & $13(36.1 \%)$ & $5(13.9 \%)$ & $10(27.8 \%)$ & $8(22.2 \%)$ & - \\
\hline Material:BT & - & - & - & - & - \\
(G1) OC-Direct & $2(15.4 \%)$ & $8(61.5 \%)$ & $2(15.4 \%)$ & $1(7.7 \%)$ & - \\
(G2) BO-Direct & $8(61.5 \%)$ & $3(23.1 \%)$ & $1(7.7 \%)$ & $1(7.7 \%)$ & - \\
(G3) OC-Direct & $2(15.4 \%)$ & $8(61.5 \%)$ & $2(15.4 \%)$ & $1(7.7 \%)$ & - \\
(G4) XT-Indirect & $1(8.3 \%)$ & $2(16.7 \%)$ & $4(33.3 \%)$ & $5(41.7 \%)$ & - \\
(G5) BO-Indirect & $11(91.7 \%)$ & $1(8.3 \%)$ & $0(0 \%)$ & $0(0 \%)$ & - \\
(G6) OC-Indirect & $1(8.3 \%)$ & $2(16.7 \%)$ & $6(50 \%)$ & $3(25 \%)$ & - \\
\hline
\end{tabular}

Different letters $\left({ }^{a}, b\right)$ show significant statistical difference.

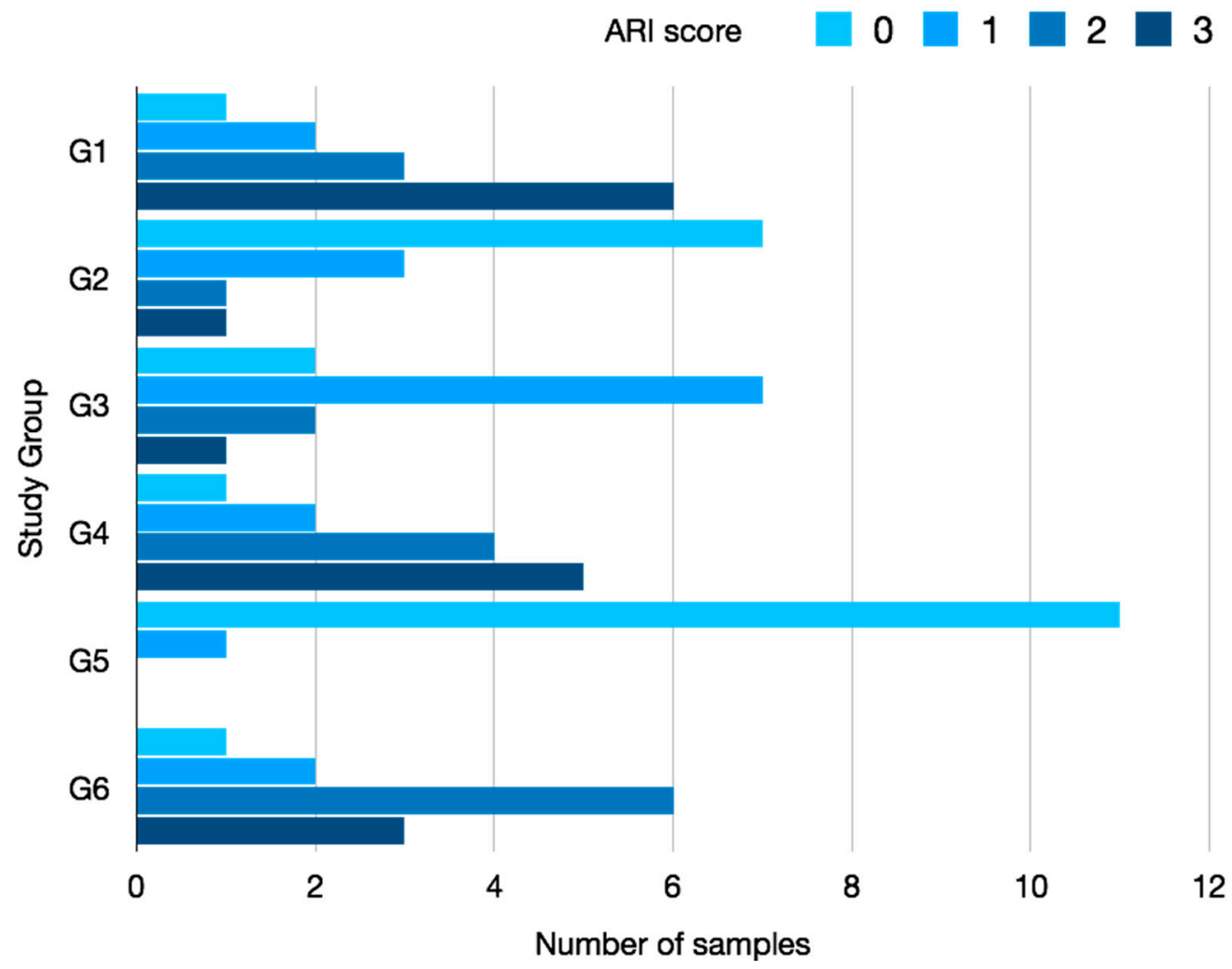

Figure 5. Bar diagram of ARI classification according to groups.

Group 1 exhibited the highest ARI scores, which represented the most composite remaining on the enamel surface, while the lowest ARI score (least composite remaining) was observed in Group 5.

\section{Discussion}

This investigation intended to analyze whether the reduction of clinical steps in the two bonding materials had an influence on SBS results when compared to the conventional etch bonding resin procedure in both direct and indirect bonding procedures. Moreover, we also compared how ARI can 
vary with the use of different bonding systems and bonding techniques to evaluate enamel conditions and make assumptions about which step of the bonding procedure may cause failures in adhesion.

The limitations of any in vitro study includes variables of the intra-oral environment such as saliva contamination, enamel composition, or occlusal forces, that greatly influence adhesion and can alter the results of similar in vivo studies. We tried to mitigate these differences by thermocycling all samples up to 1500 cycles [12]. Even so, the conclusions of an in vitro study cannot be directly extrapolated to the clinical environment. As such, it is important to reproduce these parameters in further randomized clinical trials and then compare the results with the present study. Moreover, other very common intra-oral situations, such as the presence of zirconia prosthetics, the demand for aesthetic ceramic brackets, or the influence of external conditions like magnetic resonance exposition, that have been reported to influence SBS could not be evaluated in our in vitro study [25-28]. However, further studies can be designed to check the behavior of the materials in these common clinical situations.

All 72 premolars were randomly allocated to the six groups of study. Even though we were not able to perform intra-operator tests for the SBS trials, all debonding mechanical tests were performed by an experienced orthodontist in this field (A.I.) and supervised by a senior researcher in bonding materials (T.F.). Premolars are the most commonly used teeth for this kind of study as their availability is not in conflict with the ethics committee due to frequent extraction for therapeutic orthodontic reasons. In addition, it is advisable to use the same teeth, since the area of the bracket mesh is necessary to obtain the MPa conversion, and having several types of bracket widths could be a variable to take into account.

We compared three different bonding materials in which the conventional acid-etching primer composite (XT) served as a control group to compare the two other novel bonding types (BO and OC). As far as we know, the self-etching system used in our study has not been commercialized and was loaned for testing in the university without any commercial interest. At the time of this study, there was no literature concerning the self-adhering system we used either. From the clinical point of view, any reduction of steps represents an improvement of the technique, reducing potential mistakes by the operator between steps, and reducing chair time. For this reason, we found the new bonding materials to be of interest for this research.

The indirect bonding technique emerged as an alternative to reduce operator stress during chair time and achieve a more accurate placement of the bracket from the beginning of the treatment [29-31] Re-bonding brackets is an enamel endangering procedure that is commonly practiced in orthodontics. The process of bracket replacement increases the enamel loss previously mentioned in initial bonding $[7,32]$ as well as in the new pre-treatment of the enamel and the posterior final debonding. On this matter, the indirect bonding technique showed no statistically significant difference in any of the groups when compared with its direct bonding analogs, indicating it is an optimal bonding technique [13,33-36]. Although other authors reported significantly lower values of SBS in indirect bonding samples when compared with direct bonding [12,37], it must be pointed out that many studies are difficult to compare because of the numerous steps. The lack of standardization in indirect techniques adds variables concerning the material of the trays [38-40], the adhesion system (light or chemical cured), and even the type of brackets and positioning guides (slot heights, center of crown, parallelism guide) [41].

The bond strength of orthodontic appliances must be able to withstand intra-oral forces during treatment. An optimal adhesion with SBS minimum values of 5.9-7.8 $\mathrm{MPa}$ [4] must be reached independently of the type of material or the bonding technique. The Beauty Ortho Bond II (BO), eliminated the two-step presentation of primers A and B (conditioning and priming) of its predecessor into a single bottle mixture of the monomer primer. However, this material showed values of SBS that were below the minimum necessary forces previously described [4], and significantly lower than the acid-etching groups. No other literature reference was found to analyze a correlation or establish where the failure might have occurred. Its predecessor, the Beauty Ortho Bond, has been widely studied as one of the standards for self-etching orthodontic materials in comparison with conventional bonding systems $[3,8,12,42-45]$. Therefore, it could be speculated that the bonding failure occurs at some point 
in the chemical reaction of the self-etching new "all in one" bottle presentation, and should compel the commercial brand to conduct more trials before its public sale.

The self-adhering resin simplifies the bonding process by reducing it to a one-step procedure after enamel etching. Previous studies with self-adhering flowable resins stated significantly lower SBS values when compared with conventional systems $[2,46,47]$. These initial studies tried out composites originally intended for restorative procedures instead of orthodontic purposes, which had a more liquid composition. Contrarily, the self-adhesive material used in this study has been manufactured for orthodontic use and has demonstrated effective bond strength at debonding, with similar values to the conventional acid-etching primer composite (XT) samples in agreement with previous studies [48].

Data about failure at the bracket-adhesive or the adhesive-enamel interface has both advantages and disadvantages. The tested samples revealed significantly lower values of ARI in both BO groups, in agreement with previous studies [8,12,32]. The majority of the acid-etching samples (G1, G3, G4, G6) exhibited ARI scores between 2 and 3 . When enamel surface remains relatively intact after debonding, considerable chair time is needed to remove the residual adhesive, with the risk of damaging the enamel substance also present in the cleaning procedure [32,49]. This issue can be minimized by alternative removal procedures that are less detrimental to enamel, such as sandblasting [50,51]. In the case of a failure in the enamel adhesive interface, less adhesive will remain, but the enamel surface can also be damaged when a failure occurs in this way, even producing enamel fractures [27,52]. The acid-etching group reflected an optimal union between enamel and adhesive, with high ARI values, which could also justify the higher SBS results. Meanwhile, the lower ARI values, which also corresponded to the lower SBS results, reflected a bond failure or insufficient union between the adhesive and enamel.

\section{Conclusions}

- All self-etching samples showed significantly lower shear bond strength values when compared with the acid-etching groups. $\mathrm{BO}$ samples showed values below what is recommended for clinical use (5.9-7.8 MPa).

- The self-adhesive composite groups demonstrated similar values to those of the XT that acted as a control group, illustrating that this material had efficient forces, regardless of the reduction of one clinical step.

- There were no statistical differences between the indirect bonding technique groups when compared with their direct bonding analogs. Therefore, indirect bonding technique is a valid alternative bonding procedure.

- ARI scores suggested that the acid-etching samples (with the majority of scores between 2 and 3) created an effective bonding-enamel attachment but could lead to further enamel damage during the polishing procedure.

- Further clinical studies with the same materials are necessary.

Author Contributions: Conceptualization, A.I. and T.F.; methodology, A.I.; M.A. and F.J.G.; software, A.I. and J.M.; validation, A.P., M.A. and F.J.G.; formal analysis, A.P. and M.A.; investigation, A.I.; resources, T.F.; data curation, A.I. and J.M.; writing—original draft preparation, A.I.; writing—review and editing, A.I.; J.M. and F.J.G.; visualization, J.M. and M.A.; supervision, T.F. and F.J.G. All authors have read and agreed to the published version of the manuscript.

Funding: This research received no external funding.

Conflicts of Interest: The authors declare no conflict of interest.

\section{References}

1. Newman, G.V. Epoxy adhesives for orthodontic attachments: Progress report. Am. J. Orthod. 1965, 51,901-912. [CrossRef]

2. Al-khatieeb, M.M.; Mohammed, S.A.; Al-attar, A.M. Evaluation of a new orthodontic bonding system (Beauty Ortho Bond). J. Bagh Coll Dent. 2015, 27, 175-181. [CrossRef] 
3. Buyukyilmaz, T.; Usumez, S.; Karaman, A.I. Effect of self-etching primers on bond strength-Are they reliable. Angle Orthod. 2003, 73, 64-70. [PubMed]

4. Reynolds, I.R.; von Fraunhofer, J.A. Direct bonding of orthodontic attachments to teeth: The relation of adhesive bond strength to gauze mesh size. Br. J. Orthod. 1976, 3, 91-95. [CrossRef] [PubMed]

5. Scribante, A.; Contreras-bulnes, R.; Montasser, M.A.; Vallittu, P.K. Orthodontics: Bracket Materials, Adhesives Systems, and Their Bond Strength. Biomed. Res. Int. 2016, 2016, 10-12. [CrossRef] [PubMed]

6. Lamper, T.; Nicoleta Ilie, K.C.H. Self-etch adhesives for the bonding of orthodontic brackets: Faster, stronger, safer. Clin. Oral Investig. 2014, 18, 313. [CrossRef] [PubMed]

7. Graber, L.W.; Vanarsdall, R.L.; Vig, K.W.L.; Huang, G.J. Orthodontics: Current Principles and Techniques, 6th ed.; Elsevier: St Louis, MI, USA, 2017; pp. 812-867.

8. Bishara, S.E.; VonWald, L.; Laffon, J.; Warren, J.J. Effect of a self-etch primer/adhesive on the shear bond strength of orthodontic brackets. Am. J. Orthod Dentofac Orthop. 2001, 119, 621-624. [CrossRef] [PubMed]

9. Buonocore, M.; Matsui, A.; Gwinnett, A. Penetration of resin dental materials into enamel surfaces with reference to bonding. Arch. Oral Biol. 1978, 13, 61-70. [CrossRef]

10. Hung, C.-Y.; Yu, J.-H.; Su, L.-W.; Uan, J.-Y.; Chen, Y.-C.; Lin, D.-J. Shear Bonding Strength and Thermal Cycling Effect of Fluoride Releasable / Rechargeable Orthodontic Adhesive Resins Containing LiA1-F Layered Double. Materials 2019, 12, 3204. [CrossRef] [PubMed]

11. Itoh, K.; Rzdo-do, M.; Germany, W. Effect Dentin of the Self Etching Dentin Primers on the Bonding Efficacy of a Adhesive Toshie KOIKE, Tokuji Sadao WAKUMOTO and Tohru HAYAKAWA * Department of Operative Dentinstry, Showa University, School of Dentistry, 2-1-1- Kitasenzoku, Ohta-ku Tok. Dent. Mater. J. 1989, 8, 86-92.

12. Flores, T.; Mayoral, J.; Giner, L.; Puigdollers, A. Comparison of enamel-bracket bond strength using directand indirect-bonding techniques with a self-etching ion releasing S-PRG filler. Dent. Mater. J. 2015, 34, 41-47. [CrossRef] [PubMed]

13. Thiyagarajah, S.; Spary, D.J.; Rock, W.P. A clinical comparison of bracket bond failures in association with direct and indirect bonding. J. Orthod. 2006, 33, 198-204. [CrossRef] [PubMed]

14. Vicente, A.; Bravo, L.A.; Romero, M.; Ortíz, A.J.; Canteras, M. Effects of 3 adhesion promoters on the shear bond strength of orthodontic brackets: An in-vitro study. Am. J. Orthod Dentofacial Orthop. 2006, 129, 390-395. [CrossRef] [PubMed]

15. Iijima, M.; Ito, S.; Yuasa, T.; Muguruma, T.; Saito, T.; Mizoguchi, I. Bond Strength Comparison and Scanning Electron Microscopic Evaluation of Three Orthodontic Bonding Systems. Dent. Mater. J. 2008, 27, 392-399. [CrossRef] [PubMed]

16. Silverman, E.; Cohen, M.; Gianelly, A.; Dietz, V. A universal indirect bonding system for both metal and plastic brackets. Am. J. Orthod. 1972, 62, 236-244. [CrossRef]

17. Thomas, R. Indirect bonding, simplicity in action. J. Clin. Orthod. 1979, 13, 93-105. [PubMed]

18. Kalange, J.T. Indirect bonding: A comprehensive review of the advantages. World J. Orthod. 2004, 5, 301-307. [PubMed]

19. Klocke, A.; Shi, J. Bond Strength with Custom Base Indirect Bonding Techniques. Angle Orthod. 2003, 73, 176-180. [PubMed]

20. Hocevart, R.A.; Vincent, H.F. Indirect versus direct bonding: Bond strength and failure location. Am. J. Orthod Dentofac Orthop. 1988, 94, 367-371. [CrossRef]

21. Koo, B.C.; Chung, C.-H.; Vanarsdall, R.L. Comparison of accuracy of bracket placement between direct and indirect bonding techniques. Am. J. Orthod Dentofac Orthop. 1999, 116, 346-351. [CrossRef]

22. Songhi, A. Efficient and effective indirect bonding. Am. J. Orthod Dentofac Orthop. 1999, 115, 352-359. [CrossRef]

23. Flores, T.; Mayoral, J.R.; Artés, M.; Llopis, J.; Puigdollers, A. Increase in enamel volume of premolars by remineralization with s-prg filler containing toothpaste following debonding of lingual buttons: An In-vitro nanometric study. Int. J. Sci. Res. 2017, 6, 539-541.

24. Montasser, M.A.; Drummond, J.L. Reliability of the Adhesive Remnant Index Score System with Different Magnifications. Angle Orthod. 2009, 79, 733-736. [CrossRef] [PubMed]

25. Da Silva Araújo, M.; Oliveira, D.D.; Silveira, G.S.; de Fátima Ferreira, E.; Nogueira, A. Bond Strength and Failure Pattern of Orthodontic Tubes Adhered to a Zirconia Surface Submitted to Di ff erent Modes of Application of a Ceramic Primer. Materials 2019, 12, 1-9. 
26. Colombo, M.; Gallo, S.; Padovan, S.; Chiesa, M.; Poggio, C. Influence of Di ff erent Surface Pretreatments on Shear Bond Strength of an Adhesive Resin Cement to Various Zirconia Ceramics. Materials 2020, 13, 652. [CrossRef] [PubMed]

27. Ju, G.; Oh, S.; Lim, B.; Lee, H.; Chung, S.H. Effect of Simplified Bonding on Shear Bond Strength between Ceramic Brackets and Dental Zirconia. Materials 2019, 12, 1640. [CrossRef] [PubMed]

28. Sfondrini, M.F.; Preda, L.; Calliada, F.; Carbone, L.; Lungarotti, L.; Bernardinelli, L.; Gandini, P.; Scribante, A. Magnetic Resonance Imaging and Its $\mathrm{E}$ ff ects on Metallic Brackets and Wires: Does It Alter the Temperature and Bonding E ffi cacy of Orthodontic Devices. Materials 2019, 12, 3971. [CrossRef] [PubMed]

29. Shpack, N.; Geron, S.; Floris, I.; Davidovitch, M.; Brosh, T.; Dan Vardimon, A. Bracket Placement in Lingual vs Labial Systems and Direct vs Indirect Bonding. Angle Orthod. 2007, 77, 509-517. [CrossRef]

30. Ciuffolo, F.; Tenisci, N.; Pollutri, L. Modified bonding technique for a standardized and effective indirect bonding procedure. Am. J. Orthod Dentofac Orthop. 2012, 141, 504-509. [CrossRef] [PubMed]

31. Miles, P.G.; Weyant, R.J. A Comparison of Two Indirect Bonding Adhesives. Angle Orthod. 2005, 75, 1019-1023. [PubMed]

32. Bishara, S.E.; Vonwald, L.; Laffoon, J.F.; Jacobsen, J.R. Effect of altering the type of enamel conditioner on shear bond strenght of a resin-reinforced glass ionomer adhesive. Am. J. Orthod Dentofac Orthop. 2000, 118, 288-294. [CrossRef] [PubMed]

33. Polat, O.; Karaman, A.I.; Buyukyilmaz, T. In Vitro Evaluation of Shear Bond Strengths and In Vivo Analysis of Bond Survival of Indirect-Bonding Resins. Angle Orthod. 2004, 74, 19-21.

34. Parrish, B.C.; Katona, T.R.; Isikbay, S.C.; Stewart, K.T.; Kula, K.S. The effects of application time of a self-etching primer and debonding methods on bracket bond strength. Angle Orthod. 2012, 82, 131-136. [CrossRef] [PubMed]

35. Swetha, M.; Pai, V.S.; Sanjay, N.; Nandini, S. Indirect versus Direct Bonding-A Shear Bond Strength Comparison: An in vitro Study. J. Contemp Pr. 2011, 12, 232-238.

36. Daub, J.; Berzins, D.W.; James, B.; Gerard, T. Bond Strength of Direct and Indirect Bonded Brackets after Thermocycling. Angle Orthod. 2006, 76, 295-300.

37. Klocke, A.; Shi, J.; Vaziri, F. Effect of Time on Bond Strength in Indirect Bonding. Angle Orthod. 2004, 74, $245-250$. [PubMed]

38. Kalange, J.T. Ideal appliance placement with APC brackets and indirect bonding. J. Clin. Orthod. 1999, 33, 516-526. [PubMed]

39. White, L.W. A new and improved indirect bonding technique. J. Clin. Orthod. 1999, 33, 17-23. [PubMed]

40. White, L.W. An expedited indirect bonding technique. J. Clin. Orthod. 2001, 35, 36-41. [PubMed]

41. McLaughlin, R.P.; Bennet, J.; Trevisi, H. Systemized Orthodontic Treatment Mechanics; Mosby: London, UK, 2001.

42. Elekdag-turk, S.; Turk, T.; Isci, D.; Ozkalayci, N. Thermocycling Effects on Shear Bond Strength of a Self-Etching Primer. Angle Orthod. 2008, 78, 351-356. [CrossRef] [PubMed]

43. Horiuchi, S.; Kaneko, K.; Mori, H.; Kawakami, E.; Tsukahara, T.; Yamamoto, K. Enamel bonding of self-etching and phosphoric acid-etching orthodontic adhesives in simulated clinical conditions: Debonding force and enamel surface. Dent. Mater. J. 2009, 28, 419-425. [CrossRef] [PubMed]

44. Yuasa, T.; Iijima, M.; Ito, S.; Muguruma, T. Effects of long-term storage and thermocycling on bond strength of two self-etching primer adhesive systems. Eur. J. Orthod. 2010, 32, 285-290. [CrossRef] [PubMed]

45. Kitayama, S.; Nikaido, T.; Ikeda, M.; Foxton, R.M.; Tagami, J. Enamel Bonding of Self-etch and Phosphoric Acid-etch Orthodontic Adhesive Systems. Dent. Mater. J. 2007, 26, 135-143. [CrossRef] [PubMed]

46. Bishara, S.E.; Ostby, A.W.; Ajlouni, R.; Laffoon, J.F.; Warren, J.J. Early Shear Bond Strength of a One-step Self-adhesive on Orthodontic Brackets. Angle Orthod. 2006, 76, 689-693. [PubMed]

47. Ascensión, V.; Bravo, L.; Romero, M.; Ortiz, A.; Canteras, M.; Math, B. A Comparison of the Shear Bond Strength of a Resin Cement and Two Orthodontic Resin Adhesive Systems. Angle Orthod. 2005, 75, 109-113.

48. Goracci, C.; Margvelashvili, M.; Giovannetti, A.; Vichi, A.; Ferrari, M. Shear bond strength of orthodontic brackets bonded with a new self-adhering flowable resin composite. Clin. Oral Investig. 2013, 17, 609-617. [CrossRef] [PubMed]

49. Campbell, P.M. Enamel surfaces after orthodontic bracket debonding. Angle Orthod. 1995, 65, $103-110$. [PubMed] 
50. Kim, S.; Park, W.; Son, W.; Ahn, H.; Ro, J. Enamel surface evaluation after removal of orthodontic composite remnants by intraoral sandblasting: A 3-dimensional surface profilometry study. Am. J. Orthod Dentofac Orthop. 2007, 132, 71-76. [CrossRef] [PubMed]

51. Buyukyilmaz, T.; Zachrisson, B.U. Improved orthodontic bonding to silver amalgam. Part 2. Lathe-cut, admixed, and spherical amalgams with different intermediate resins. Angle Orthod. 1998, 68, 337-344.

52. Bishara, S.E.; Gordan, V.V.; Vonwald, L.; Jakobsen, J.R. Shear bond strength of composite, glass ionomer, and acidic primer adhesive systems. Am. J. Orthod Dentofac Orthop. 1999, 115, 24-28. [CrossRef]

(C) 2020 by the authors. Licensee MDPI, Basel, Switzerland. This article is an open access article distributed under the terms and conditions of the Creative Commons Attribution (CC BY) license (http://creativecommons.org/licenses/by/4.0/). 